\section{Resultados del tratamiento de espera del aborto espontáneo en el primer trimestre}

Cerca del 15\% de los embarazos identificados clínicamente son abortados espontáneamente en el primer trimestre. El tratamiento actual consiste a menudo en la evacuación quirúrgica de los productos de la concepción retenidos, aunque esta medida no está exenta de complicaciones graves, como la infección, la perforación uterina o las lesiones intestinales. Por otra parte, hay datos preliminares que indican que el tratamiento de espera, acompañado de vigilancia ecográfica, puede ser útil para identificar a las pacientes que no necesitan tratamiento quirúrgico, pero son necesarios más estudios para establecer la aceptabilidad de esta estrategia terapéutica y la relación entre la información proporcionada por la ecografía y los resultados clínicos. Con base en estas consideraciones, los autores de este artículo realizaron un estudio observacional para determinar la eficacia del tratamiento de espera en diferentes formas de presentación clínica del aborto espontáneo en el primer trimestre.

Se observaron 1096 pacientes consecutivas, no seleccionadas, con sospecha de aborto en el primer trimestre. En función de los resultados de la ecografía transvaginal, los abortos se clasificaron como completos, incompletos, retenidos o anembrionarios. A los casos clasificados como aborto completo se les pidió que informaran de cualquier otro síntoma o signo preocupante. A los de aborto retenido se les ofrecieron dos alternativas: el tratamiento de espera o la intervención quirúrgica con anestesia general; a las mujeres que eligieron la primera opción se les permitió cambiar a la otra en cualquier momento. La evolución de estas pacientes fue comprobada pocos días después del cese del sangrado vaginal o mediante exámenes semanales durante 4 semanas; a las mujeres asintomáticas, pero con aborto no completo, se les aconsejó que se sometieran a la intervención quirúrgica. Las principales medidas de eficacia fueron el aborto completo (ausencia de sangrado vaginal y grosor endometrial $<15$ $\mathrm{mm}$ ), el número de mujeres en las que el aborto se completó al final de cada una de las 4 semanas posteriores al día de la clasificación, y las complicaciones (dolor o sangrado vaginal excesivos que necesitaron hospitalización, o signos clínicos de infección).

Se excluyeron dos pacientes con embarazos molares. De las otras 1 094, 408 (37\%) tuvieron abor- tos completos y en ninguna de ellas se produjeron embarazos ectópicos $\mathrm{u}$ otras complicaciones graves que necesitaran intervención quirúrgica. De los 686 casos restantes, $478(70 \%)$ optaron por el tratamiento de espera, pero $27(6 \%)$ no acudieron a las consultas de seguimiento, con lo que quedaron 451 para el análisis. En 367 (81\%) el tratamiento de espera tuvo un resultado favorable, sin que se observaran complicaciones graves. La tasa global de aborto completo espontáneo con el tratamiento de espera fue del $91 \%(201 / 221)$ para los casos clasificados como aborto incompleto, del 76\% (105/138) para los clasificados como aborto retenido, y del 66\% (61/92) para los clasificados como embarazo anembrionario. El 52\% de los abortos incompletos se habían resuelto espontáneamente a los 7 días, y el $84 \%$ a los 14 días. Para los abortos retenidos y los embarazos anembrionarios, las cifras correspondientes fueron del $28 \%$ a los 7 días y del $56 \%$ a los 14 días. Se registraron complicaciones en 11 de las 1094 pacientes (1\%): 5 en 208 (2\%) sometidas a intervención quirúrgica inmediata, y 6 en 451 (1\%) sometidas a tratamiento de espera. Una paciente con aborto incompleto sometida a tratamiento de espera necesitó una intervención quirúrgica urgente y transfusión de sangre.

En este estudio, la mayoría de las pacientes optaron por el tratamiento de espera, posiblemente debido a que sabían que podían recurrir al tratamiento quirúrgico en caso de necesidad. La baja tasa de complicaciones registrada en las mujeres que optaron por el tratamiento de espera es tranquilizante, aunque depende de muchos factores que varían en función del ámbito en el que son atendidas las pacientes. Los resultados revelan que la ecografía transvaginal es útil para aconsejar a las pacientes con abortos espontáneos en el primer trimestre acerca de la probabilidad de que su aborto se complete de forma espontánea en las semanas siguientes. Los autores creen que los resultados de este estudio permiten aconsejar a las pacientes el tratamiento de espera, dada la elevada tasa de abortos completados espontáneamente al cabo de 2 semanas: $84 \%$ para los abortos incompletos, $52 \%$ para los abortos retenidos y los embarazos anembrionarios, y $70 \%$ en total. (Luise C, Jermy K, May C, Costello G, Collins WP, Bourne TH. Outcome of expectant management of spontaneous first trimester miscarriage: observational study. BMJ 2002;324: 873-875.) 


\section{Eficacia del aumento del número de fármacos utilizados en el tratamiento antirretrovírico combinado}

Desde 1987, fecha de la introducción de la zidovudina en el tratamiento de la infección por el virus de la inmunodeficiencia humana (VIH), el número de antirretrovíricos ha aumentado mucho y se pasó rápidamente al tratamiento combinado, primero con dos fármacos, y después con tres. Se ha propuesto incluso el tratamiento con cuatro o más fármacos. Sin embargo, no hay datos publicados sobre la eficacia de este aumento del número de fármacos utilizados en el tratamiento combinado. Con el fin de investigar la eficacia de esta estrategia, los autores del presente estudio realizaron una revisión sistemática y un metaanálisis de los ensayos clínicos aleatorios controlados que han comparado la cuádruple y la triple terapia, la triple y la doble terapia, la biterapia y la monoterapia o la monoterapia y el placebo o la ausencia de tratamiento.

La búsqueda bibliográfica de los ensayos clínicos aleatorios controlados se efectuó en diferentes bases de datos, como Medline y Embase. Además se contactaron las compañías farmacéuticas. La búsqueda incluyó los artículos publicados hasta el final de febrero de 2001. Se incluyeron los estudios en los que habían participado pacientes de más de 12 años de edad con infección por el VIH en cualquier estadio. Para reducir la potencial confusión derivada de la resistencia a los antirretrovíricos, solo se investigaron pacientes que no habían recibido tratamientos antirretrovíricos anteriormente. Las intervenciones aceptadas consistieron en cualquier fármaco o combinación de antirretrovíricos aprobados en el Reino Unido o Estados Unidos, comparadas con cualquier otro antirretrovírico o combinación de antirretrovíricos, con el placebo o con la ausencia de tratamiento. Se excluyeron los estudios de duración inferior a 12 semanas. Las principales medidas de eficacia fueron los cambios en la progresión de la enfermedad o la mortalidad, los recuentos de linfocitos T CD4 y la carga vírica plasmática.

De los 2000 artículos encontrados, en esta revisión sistemática se incluyeron 90 , referidos a 54 ensayos clínicos diferentes, la mayoría de buena calidad, que incluyeron un total de 20404 pacientes. Más del $80 \%$ de los participantes eran varones; la edad media osciló en los diferentes estudios entre 27 y 40 años. Había más pacientes asintomáticos que en cualquier otro estadio de la infección. Los recuentos basales medios de linfocitos T CD4 oscilaron entre 83 y 660 células $/ \mu \mathrm{L}$, y la carga vírica basal media entre 2,35 y 7,35 log copias/mL. La duración de los ensayos clínicos fue de 12 semanas a 4,8 años.

La única monoterapia comparada con el placebo o la ausencia de tratamiento fue la zidovudina.
Los tratamientos dobles más frecuentes consistieron en dos nucleósidos, comparados con la monoterapia con zidovudina o didanosina. Los tratamientos triples consistieron sobre todo en las combinaciones actualmente recomendadas de dos nucleósidos (generalmente zidovudina más didanosina o lamivudina) más un inhibidor de la proteasa (IP) o un no nucleósido.

En comparación con el placebo, la monoterapia con zidovudina proporcionó una reducción significativa de la progresión de la enfermedad y de la mortalidad (razón de posibilidades [OR]: 0,7; intervalo de confianza del 95\% [IC95]: 0,6 a 0,8), aunque hubo una considerable heterogeneidad (OR entre 0,1 y 1,1), explicable, en parte, por la variabilidad de la duración de los estudios clínicos. El efecto relativo de la zidovudina disminuyó a medida que aumentó la duración de los estudios. La zidovudina también aumentó el recuento de linfocitos T CD4 en un promedio de 47 células/ $\mu \mathrm{L}$ (IC95: 29 a 65) y disminuyó la carga vírica en 0,56 log copias/mL (IC95: 0,71 a 0,41 ).

En comparación con la monoterapia, el tratamiento con dos antirretrovíricos ocasionó una significativa reducción de la progresión de la enfermedad y de la mortalidad (OR: 0,6; IC95: 0,5 a 0,7). Aunque hubo alguna heterogeneidad, parecía deberse en gran parte a un solo estudio, cuya exclusión del análisis no modificó el tamaño del efecto ni los IC95. Los resultados referidos al recuento de linfocitos T CD4 y a la carga vírica también mostraron una mejoría significativa con la biterapia. El análisis de la heterogeneidad con respecto a los recuentos de linfocitos T CD4 reveló que se debía únicamente a la presencia de zidovudina o IP, lo cual indica que las combinaciones que contienen IP pueden ser más eficaces que otros tratamientos dobles, y que la monoterapia con zidovudina es menos eficaz que otras monoterapias.

El tratamiento con tres fármacos también mejoró significativamente los resultados clínicos (progresión de la enfermedad y mortalidad) en comparación con el tratamiento con dos fármacos (OR: 0,6; IC95: 0,5 a 0,8). La heterogeneidad fue atribuible a un único estudio, cuya exclusión no alteró el tamaño del efecto. Los resultados con respecto a los recuentos de linfocitos T CD4 y a la carga vírica mostraron una tendencia similar.

Veintiséis estudios también proporcionaron información sobre los abandonos del tratamiento relacionados con los fármacos. Las tasas de abandonos fueron mayores con la monoterapia que con el placebo, pero no hubo diferencias en este aspecto entre la monoterapia y la biterapia. Los resultados de la comparación entre la doble y la triple terapia fueron heterogéneos. No hubo diferencias en la tasa de abandonos entre la doble y la triple terapia sin 
IP; en cambio, cuando se incluyeron fármacos de esta clase, dicha tasa fue mayor con la triple terapia que con la doble terapia.

Esta revisión sistemática aporta nuevas pruebas de la eficacia de la estrategia consistente en aumentar hasta tres el número de fármacos utilizados en el tratamiento antirretrovírico combinado. Sin embargo, todavía no hay datos suficientes que avalen la mayor eficacia de los tratamientos combinados con cuatro o más antirretrovíricos; tan importante como demostrar la eficacia de estos tratamientos será determinar cuáles son las combinaciones más eficaces de tres fármacos. Los análisis exploratorios de la heterogeneidad de los resultados indican que el diseño de futuros estudios clínicos debería ser más riguroso y menos variable en aspectos como la duración del tratamiento, los fármacos investigados o el estadio clínico de la infección al comenzar el estudio. Dicha heterogeneidad se relacionó en gran medida con los fármacos utilizados y la calidad de los estudios. (Jordan R, Gold L, Cummins C, Hyde C. Systematic review and meta-analysis of evidence for increasing numbers of drugs in antiretroviral combination therapy. BMJ 2002;324:757-760.)

\section{Eficacia de tres regímenes breves de zidovudina y lamivudina en la prevención de la transmisión vertical del VIH-1 en tres países africanos}

En 1994, un estudio realizado en los Estados Unidos y Francia demostró que el tratamiento materno con zidovudina durante el embarazo y el parto, seguido del tratamiento del recién nacido durante las primeras 6 semanas de vida, reduce la transmisión maternoinfantil del virus de la inmunodeficiencia humana de tipo 1 (VIH-1) en aproximadamente un $66 \%$. Desde entonces, en los países desarrollados se ha conseguido una gran reducción de la transmisión vertical del virus con diferentes regímenes antirretrovíricos. Además, se ha demostrado que la cesárea también reduce las tasas de transmisión. Sin embargo, la mayoría de los casos de transmisión maternoinfantil del VIH-1 ocurren en los países en desarrollo, sobre todo en África, y los tratamientos que tanto éxito han tenido en los países desarrollados son demasiado complejos y caros para poder ser aplicados a gran escala en países en desarrollo. Esto ha llevado a la realización de varios estudios que han tratado de simplificar dichos tratamientos, centrándose en el período perinatal. En este sentido, varios estudios realizados en Tailandia y África han demostrado la eficacia de la monoterapia a corto plazo con zidovudina o nevirapina para reducir la transmisión perinatal del VIH-1.

En este estudio, en vez de la monoterapia se utilizó la combinación de zidovudina y lamivudina en tres regímenes diferentes: el primero aplicado durante los períodos preparto, intraparto y posparto, el segundo durante los períodos intraparto y posparto, y el tercero únicamente durante el período intraparto. Se investigó la eficacia de estos tres regímenes a las 6 semanas y a los 18 meses del parto en una población que, en su mayoría, recibió lactancia natural.

El estudio, aleatorizado, doblemente enmascarado y controlado con placebo se realizó en cinco grandes hospitales de tres países africanos: dos de Sudáfrica, uno de Tanzania y dos de Uganda. Entre junio de 1996 y enero de 2000 se asignaron aleatoriamente embarazadas infectadas por el VIH-1 a uno de los cuatro regímenes siguientes: A) $300 \mathrm{mg}$ de zidovudina más $150 \mathrm{mg}$ de lamivudina dos veces al día, desde las 36 semanas de gestación hasta el inicio del parto; al comenzar el parto, las mujeres recibieron $300 \mathrm{mg}$ de zidovudina y $150 \mathrm{mg}$ de lamivudina, seguidos de $300 \mathrm{mg}$ de zidovudina cada $3 \mathrm{~h}$ y $150 \mathrm{mg}$ de lamivudina cada $12 \mathrm{~h}$ hasta el final del parto; durante los 7 días siguientes, las madres recibieron $300 \mathrm{mg}$ de zidovudina más $150 \mathrm{mg}$ de lamivudina dos veces al día, y los recién nacidos, $4 \mathrm{mg} / \mathrm{kg}$ de zidovudina más $2 \mathrm{mg} / \mathrm{kg}$ de lamivudina dos veces al día. B) igual que el régimen $\mathrm{A}$, pero sin un componente preparto y con la diferencia de que la primera dosis intraparto de zidovudina fue de $600 \mathrm{mg}$, en vez de $300 \mathrm{mg}$. C) igual que el régimen $\mathrm{B}$, pero sin el componente posparto, o D) placebo. A partir de febrero de 1998, las pacientes solo fueron asignadas aleatoriamente a alguno de los tratamientos activos. Las principales medidas de la eficacia de los tratamientos fueron las tasas de infección y de mortalidad de los niños a las 6 semanas y a los 18 meses.

Los criterios de inclusión fueron: edad igual o superior a 18 años; pruebas de infección por VIH-1; consentimiento esclarecido; edad gestacional estimada inferior a 36 semanas en el momento de la inclusión en el estudio; ausencia de malformaciones fetales graves detectables con los medios disponibles; ausencia de enfermedades maternas potencialmente mortales; hemoglobinemia $>8 \mathrm{~g} / \mathrm{dL}$ al comienzo del estudio, y posibilidad de efectuar el seguimiento durante 18 meses. Las consultas de seguimiento se efectuaron a las 1,3 y 6 semanas, y a $\operatorname{los} 3,6,9,12,15$ y 18 meses. Excepto en la segunda, en todas ellas se obtuvieron muestras de sangre del lactante para detectar la presencia de infección por el VIH-1 con diferentes pruebas.

Se realizó un análisis por intención de tratar en el que solo se incluyeron los casos reclutados antes de febrero de 1998, puesto que en esa fecha se decidió no incluir más casos en el grupo tratado con placebo, después de que un estudio clínico realizado en Tailandia demostrara que el tratamiento 
breve con zidovudina reduce en un 50\% la transmisión maternoinfantil del VIH-1.

En el análisis se incluyeron 1797 mujeres infectadas por el VIH-1. A las 6 semanas, las tasas de transmisión del virus fueron del $5,7 \%$ en el grupo A, del $8,9 \%$ en el $\mathrm{B}$, del $14,2 \%$ en el $\mathrm{C}$, y del $15,3 \%$ en el D. En comparación con el grupo tratado con placebo, los riesgos relativos de transmisión del VIH-1 fueron de 0,37 (intervalo de confianza del 95\% [IC95]: 0,21 a 0,65) en el grupo A, 0,58 (IC95: 0,36 a 0,94) en el B, y 0,93 (IC95: 0,62 a 1,40) en el C. Para la combinación de ambas medidas de eficacia (la infección por VIH-1 y la mortalidad infantil) a las 6 semanas, las tasas fueron del 7,0\% en el grupo $\mathrm{A}$, del $11,6 \%$ en el B, del $17,5 \%$ en el C, y del $18,1 \%$ en el D, y los correspondientes riesgos relativos, de 0,39 (IC95: 0,24 a 0,64) en el grupo A, de 0,64 (IC95: 0,42 a 0,97) en el B, y de 0,97 (IC95: 0,68 a 1,38) en el C. El $74 \%$ de las mujeres analizadas $(n=1081)$ dieron de mamar a sus hijos durante un período mediano de 28 semanas (intervalo intercuartílico: 7 a 59 semanas). De acuerdo con los resultados de un análisis de supervivencia, las tasas de infección por VIH-1 a los 18 meses fueron del 15\% (IC95: 9 a 23\%) en el grupo A, del 18\% (IC95: 12 a 26\%) en el B, del 20\% (IC95: 13 a 30\%) en el C, y del 22\% (IC95: 16 a 30\%) en el D.

El parto por cesárea y los recuentos elevados de linfocitos T CD4 se asociaron a una disminución del riesgo de transmisión del VIH-1 a las 6 semanas: razón de posibilidades (OR) de 0,60 (IC95: 0,41 a 0,87) para la cesárea, y de 0,89 (IC95: 0,83 a 0,95) por cada aumento de 100 linfocitos T CD4. A los 18 meses, los recuentos elevados de linfocitos T CD4 se asociaron a una disminución del riesgo (OR: 0,87; IC95: 0,83 a 0,92), y la lactancia materna a un aumento del riesgo (OR: 2,18; IC95: 1,50 a 3,17).

El régimen A proporcionó una reducción de la transmisión del VIH-1 del 63\% 6 semanas después del parto, aunque puede seguir siendo demasiado complejo y caro en países en desarrollo. Lamentablemente, el régimen más sencillo, el $C$, no fue superior al placebo, pero el régimen $\mathrm{B}$ proporcionó una reducción de la transmisión del VIH-1 del $42 \%$, cifra que puede considerarse aceptable. Sin embargo, aunque los regímenes A y B fueron eficaces para reducir la transmisión vertical del virus a las 6 semanas del parto, sus beneficios disminuyeron considerablemente al cabo de 18 meses, hecho atribuible a la lactancia materna y a la consiguiente transmisión del virus por esta vía. Por lo tanto, los autores concluyen que la introducción en los países subdesarrollados de regímenes breves para evitar la transmisión maternoinfantil del VIH-1 debería acompañarse de medidas para reducir el riesgo de transmisión posterior a través de la lactancia materna. (The Petra study team. Efficacy of three short-course regimens of zidovudine and lamivudine in preventing early and late transmission of HIV-1 from mother to child in Tanzania, South Africa, and Uganda (Petra study): a randomised, double-blind, placebo-controlled trial. Lancet 2002; 359:1178-1186.) 